\title{
Together for the Future - Development of a Digital Website to Support Chronic Obstructive Pulmonary Disease Self-Management: A Qualitative Study
}

This article was published in the following Dove Press journal: Journal of Multidisciplinary Healthcare

\section{Anna Kjellsdotter $\mathbb{D}^{1,2}$ \\ Susanne Andersson ${ }^{3,4}$ \\ Mia Berglund ${ }^{2}$}

'Research and Development Centre, Skaraborg Hospital, Skövde, Sweden;

${ }^{2}$ School of Health Sciences, Skövde

University, Skövde, Sweden;

${ }^{3}$ Department of Health Sciences, University West, Trollhättan, Sweden;

${ }^{4}$ Research, Education, Development \& Innovation, Primary Health Care, Region Västra Götaland, Sweden
Correspondence: Anna Kjellsdotter Research and Development Centre, Skaraborg Hospital Skövde, Skövde, S-54I 85 , Sweden

Tel +46768051962

Email anna.kjellsdotter@vgregion.se
Background: Symptom burden, impaired functional performance and decreased quality of life are not only consequences of the underlying physiological disorder chronic obstructive pulmonary disease (COPD) but also dependent on a patient's ability to learn to live with and manage their illness. A digital website may be important for empowering patients with COPD to learn about and self-manage their illness. The aim of this study was to describe a developing process of a digital COPD-web as a part of a self-management education program for persons living with COPD.

Methods: A qualitative approach with a phenomenological perspective was used. The study was based on group and individual interviews with a multidisciplinary COPD-team and patients who developed the COPD-web.

Results: The developing process appears as a person-centred and holistic self-care approach both in content and development. Developing a digital COPD-web requires ongoing multidisciplinary collaboration and spawns a sense of pride that reinforces shared responsibility. The phenomenon consists of four constituents: learning by participating in development, the patient perspective as guiding approach, responsibility and motivation as driving forces and digital technology as a knowledge arena.

Conclusion: The results indicate that constructive collaboration between a multidisciplinary COPD-team and patients as co-creators in an ongoing creative and reflective process is a key concept to develop a digital COPD-web with a holistic approach. Digital resources in the future might create time and space for reflective conversations in a COPD-web with virtual chatrooms. Keywords: COPD-team, digital tool, self-management, sustainable learning, patient involvement

\section{Background}

The rising prevalence of long-term illness is a major clinical and public health challenge. ${ }^{1}$ As resources in healthcare are unlikely to increase in future, alternative solutions need to be established today. One way to attain more effective healthcare is to increase self-management ability by offering structured patient education with interprofessional support in combination with digital technology. ${ }^{2,3}$ Ongoing research is developing and deepening eHealth knowledge in the care of long-term illnesses, ${ }^{4}$ this study focuses on chronic obstructive pulmonary disease (COPD). For patients, such solutions should be easy to handle, increase safety and lead to an improved health situation with a higher quality of life, as well as be designed with patient input. ${ }^{4,5}$ 
Persons diagnosed with COPD have various difficulties depending on the stage of the illness. For persons with more severe COPD, this often leads to major limitations in everyday life and even social isolation. ${ }^{6}$ Lack of knowledge and insight is common in persons with COPD, and they may endure feelings of guilt, shame and fear while trying to manage and accept their illness. ${ }^{7}$ To manage COPD and symptom self-control, it is important that professionals proactively support patients' health resources and confidence in their abilities, participation and decision-making in their own care. ${ }^{8,9}$ Indeed, together with professionals, patients are an important source of development co-creation that improves knowledge, awareness and understanding of long-term illnesses. ${ }^{10}$

The WHO predicts that COPD will rank third in world mortality by $2030 .^{11}$ Today, it is estimated that $500,000-$ 700,000 people in Sweden have COPD, but this prevalence is rising. ${ }^{12}$ The progress of COPD is not fully reversible with treatment due to permanent lung damage, but can be slowed through, for example, self-management activities. ${ }^{13}$ The illness is progressive and people with it often have great care needs. ${ }^{2,13}$ COPD is a common comorbidity of cardiovascular diseases, diabetes, hypertension, depression and others. ${ }^{14,15}$ COPD also includes acute periods of exacerbation, which accelerate its progression. Several periods of exacerbation during the year entail a prognostic risk of severe deterioration and death, especially if hospitalization is required. ${ }^{12}$ The goal for all COPD treatments is for patients to achieve as much selfcontrol as possible over their illness.

Given this goal, COPD treatment should be personcentred. Person-centred care focuses on the patient as an active partner in care and treatment, ${ }^{16}$ integrating their experiences, needs, resources and condition. A holistic approach means to see the person as "a whole" by making distinctions between holistic care and care or treatment addressing the physical body only. ${ }^{17}$ By strengthening the patient's motivation for increased self-management, the patient is more likely to seek appropriate and timely care. Person-centred patient education, smoking cessation, training and interprofessional self-management support are crucial elements in treating COPD specifically. ${ }^{9,18}$

Self-management education is a high priority in the Swedish National Guidelines for Asthma and COPD. ${ }^{12}$ Studies show that the care of persons with COPD has a higher value when based on interprofessional collaboration. ${ }^{19}$ Indeed, the goal of COPD selfmanagement education is to optimize quality of life, increase independence, maintain a stable health condition as long as possible and prevent periods of exacerbation in patients living with COPD. ${ }^{9,19}$ Person-centred care should therefore dominate COPD treatment, as it emphasizes patients' own needs and team participation. ${ }^{20}$ In line with person-centred care, to support patients' self-management, professionals need to increase patient involvement, which in turn implies a need to change routines and establish new ways of organizing and administering care.

\section{A COPD-Web Developed by a Multidisciplinary Team and Patients}

The patients living in the region of the study hospital in southern Sweden are offered a COPDschool in line with the Swedish National Board of Health's guidelines for asthma and COPD. ${ }^{12}$ The COPDschool is divided into different education blocks consisting of four occasions à 2 hours (Table 1). Group size usually varies between 8 and 10 persons with COPD and their relatives to strengthen each group's dynamics. The COPD-team that developed the COPDschool consists of 14 professionals who can provide support and education (Table 2).

To further develop the COPDschool with a digital website (COPD-web), patients were recruited to the

Table I Group Session Themes at the COPDschool

\begin{tabular}{|l|l|l|}
\hline Session I & $\begin{array}{l}\text { COPD, treatment, medication and psychosocial support } \\
\text { Introduction to the COPD web }\end{array}$ & $\begin{array}{l}\text { COPD-nurse, Physician, Pharmacist, Speech therapist, Social worker and } \\
\text { the local patient organization HeartLung }\end{array}$ \\
\hline Session 2 & $\begin{array}{l}\text { The importance of food to COPD, oral health and } \\
\text { energy-saving methods in daily life }\end{array}$ & Dietician, Dental hygienist, Occupational therapist \\
\hline Session 3 & $\begin{array}{l}\text { Self-care, breathing and coughing techniques and physical } \\
\text { activity }\end{array}$ & Physiotherapist \\
\hline Session 4 & $\begin{array}{l}\text { Physical exercise (practice), including pelvic floor } \\
\text { exercises }\end{array}$ & Physiotherapist, Urotherapist \\
\hline
\end{tabular}


Table 2 Professions and Their Responsibilities in the COPD-Team

\begin{tabular}{|c|c|}
\hline Profession & Responsibility \\
\hline Social worker & $\begin{array}{l}\text { \#Driving force in the project; informs on patient rights in hospitals and in society; emotional, informative, financial and } \\
\text { practical support }\end{array}$ \\
\hline Assistant nurse & ${ }^{\ddagger}$ Hygiene issues \\
\hline COPD-nurse & ${ }^{\dagger \ddagger}$ Lifestyle changes, examination with spirometry \\
\hline Dental hygienist & ${ }^{\ddagger}$ Oral health; informs about economic dental grant \\
\hline Dietician & †‡Dietary guidelines \\
\hline Librarian & ${ }^{\ddagger}$ Evidence-based information search \\
\hline $\begin{array}{l}\text { Occupational } \\
\text { therapist }\end{array}$ & †‡Utilities in everyday life, energy-saving methods \\
\hline Physician & †‡Facts about COPD \\
\hline Physiotherapist & ${ }^{\dagger \ddagger}$ Breathing and coughing techniques, relaxation, energy-saving methods, mobility, strength and stretching \\
\hline Pharmacist & ${ }_{\ddagger}$ COPD drugs, self-care at mild deterioration, vaccinations \\
\hline Priest & ${ }^{\ddagger}$ Existential health \\
\hline Speech therapist & ${ }^{\dagger}$ Speaking exercises, swallowing difficulties \\
\hline Sexologist & ${ }^{\ddagger}$ Resource for sexual health concerns \\
\hline Urotherapist & ${ }^{\dagger}$ Incontinence, pelvic floor exercises \\
\hline
\end{tabular}

Notes: ${ }^{\dagger}$ COPDschool; ${ }^{\ddagger}$ COPD-web; range of professionals' experience: I-30 years.

COPD-team. This work started in 2013 and is still an ongoing process. The purpose was to create an interactive and virtual service system that empowers patients with COPD. The COPD-team continuously received technical support from regional developers working with healthcare digitalization and experts working with image and media at the local hospital. To ensure good usability technical expertise was included early in the developing process. The COPD-web was made self-instructional and divided into three main themes: Facts about COPD, Selfmanagement and treatment and Facilitating everyday life (The COPD-web). Under each theme were several sections containing one or more texts, pictures and films (Figure 1). Users of the COPD-web who wish to immerse themselves can access more in-depth knowledge through links, too, among others, the National Health Guide and the Swedish Heart and Lung Association. This work was in line with experience-based co-design. ${ }^{21,22}$ In this study, the professionals and patients collaborated during the developing process of the content, design and implementation of the COPD-web as equivalent COPD-team members.

The aim of this study was to describe a developing process of a digital COPD-web as a part of a self- management education program for persons living with COPD.

\section{Methods} Design

We followed a qualitative research approach to explore and illuminate the phenomenon of interest "developing a digital COPD-web", ie, professionals, representing a COPD-team, and patients with COPD developed a digital COPD website (COPD-web). The Reflective Life-world Research (RLR), based on phenomenological philosophy, is developed by Dahlberg et al. ${ }^{23}$ The research focuses on how people live and describe everyday phenomena to clarify individual human experiences.

\section{Setting and Participants}

This study's participants were professionals and patients recruited from a central hospital in southern Sweden and who developed the digital website. All 14 professionals were included, and together they had much experience caring for people with COPD (Table 1). The project also included eight patients with COPD (both men and women) 


\section{The COPD-web}

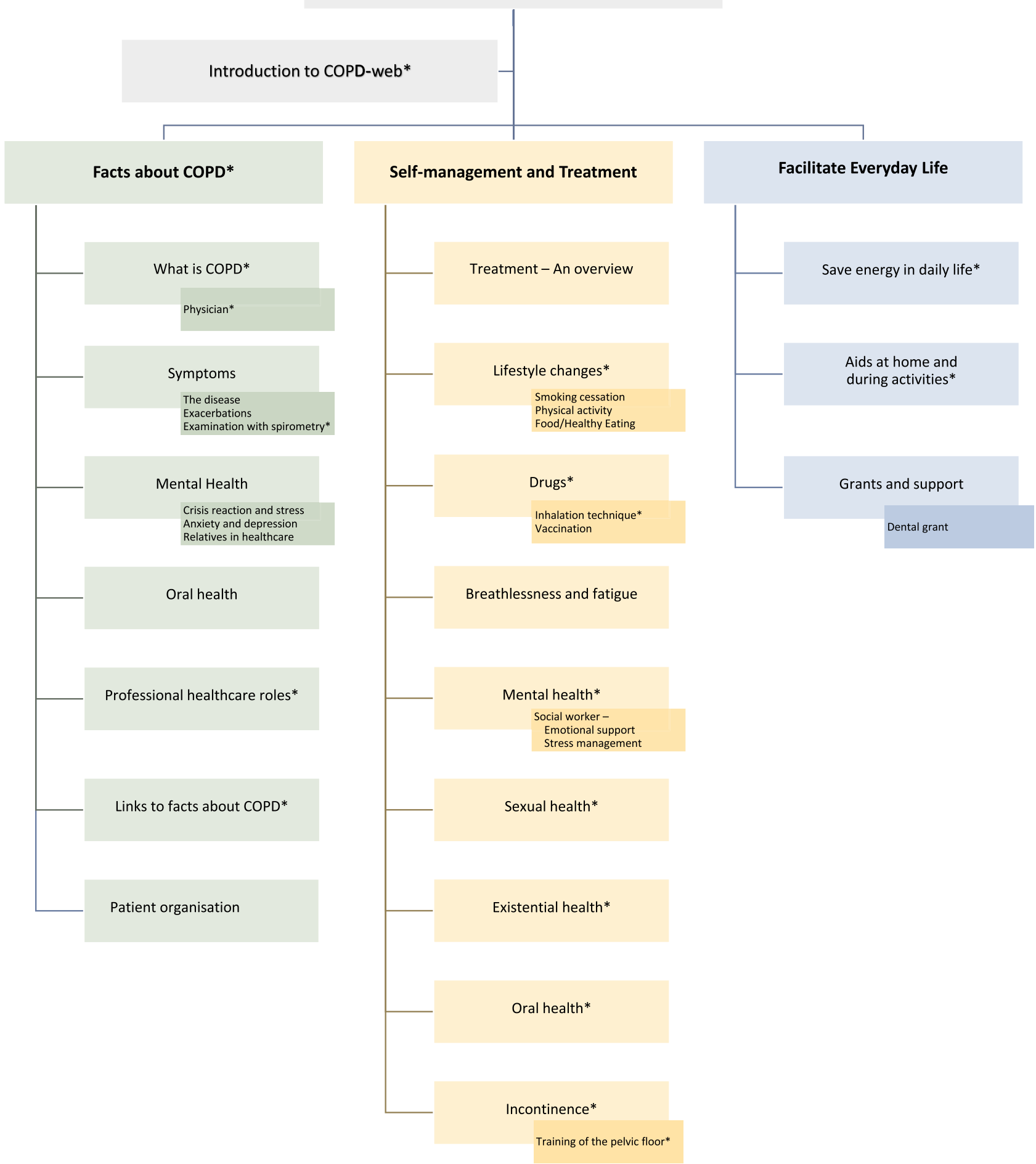

Figure I In the image above all themes contain factual texts and pictures, *also contain films. Some themes are exemplified by subthemes. 
at an age range of 62-82 years who had participated in the COPDschool.

\section{Data Collection}

Three group interviews were conducted, at the hospital, two with 11 of the professionals and the other with five patients. Three of the professionals were unable to participate in the interview due to other engagements at the time. We conducted three further individual patient interviews by phone as they were prevented from participating in the group interview. The interviews utilized open-ended questions addressing the phenomenon "developing a digital COPD-web". The opening question was: "How have you developed the digital self-care education/digital website for persons with COPD?" Followed by "Please, describe how the work started and developed over time, describe your roles and expectations".

In-depth question as "can you give an example?", "can you describe more?" were used. Each group interview lasted about $90 \mathrm{~min}$, while the individual interviews lasted 32-45 min. The interviews were carried out as a dialogue to enable reflection on the phenomenon of interest. ${ }^{22}$ The interviews were digitally recorded and transcribed verbatim.

\section{Data Analysis}

Phenomenological research requires an open and sensitive attitude and the researchers involved must bridle their understandings throughout the research process. According to Dahlberg et al, ${ }^{23}$ bridling is the researcher's guiding tool which requires a conscious, critical and reflective attitude striving to increase the understanding of the phenomenon.

All data is seen as one whole piece of text. In the first analysis phase, the text was read in an open manner to become familiar with the data. The data were then divided into sequences (units) with their own meaning. The meaning units were further reflected against the whole data. In the next phase, groups of meaning were built up as clusters. In the cluster analysis, a pattern emerged and the essence formed. This can be described as an abstract synthesis of the phenomenon's unique structure of meanings, which creates a new whole, ${ }^{23}$ on a more concrete level, the phenomenon becomes nuances or constituents illustrated with interview quotes.

\section{Results}

The phenomenon, developing a digital COPD-web, requires collaboration in an ongoing process, which triggers a sense of pride that reinforces shared responsibility. The patients and professionals share experiences and critically examine and learn from each other in their ambition to share knowledge about living with COPD. The ambition is to generate a living, sustainable and practically useful digital platform, without having anyone affected by COPD feel guilty or ashamed. The developing process is an interprofessional, person-centred and holistic self-care approach that considers a whole person, meaning physical, mental, sexual and existential health, both in content and development.

The phenomenon is enlightened by four constituents: learning by participating in development, the patient perspective as guiding approach, responsibility and motivation as driving forces, digital technology as a knowledge arena.

\section{Learning by Participating in Development} Experiences from developing a digital COPD-web entail learning what takes place when a multidisciplinary team and patients actively participate in the actual creation process. The different professionals learn from each other's experiences, through which roles and responsibilities are clarified and discussed. They also describe the common learning as fun, inspiring and evolving, which contribute to an increased overall view.

A special understanding develops as the professionals receive feedback from the patients as well. As the patients read and discuss texts and record films, their own understanding increases and they learn more about themselves and what they were experiencing, such as fatigue:

"But then it comes up - I could not understand why I was so extremely tired. Then we had a discussion about this, on fatigue. Gee, of course, I thought. That is why I can wake up in the morning and still be tired."

The professionals further describe a common and individual learning (ie, building the website and applying digital technology) in their professional work: "So when we put together our perspective, our highlights and the patients', it was something completely new to us too." Both the professionals and the patients describe pride in being part of and contributing to this knowledge source, thus supporting patients, relatives and other professionals:

"We are proud of having done this. We feel lucky. Participating in the group has been intense, we have been committed and learned a lot."

The shared understanding of patients and professionals as co-producers is that the developing process creates new 
knowledge of treatment and of daily life living with COPD. They describe pride in having received a national and international attention for the COPD-web. In response, the participants desired to continue to develop and learn more about COPD.

\section{The Patient Perspective as Guiding Approach}

The COPD-web development implies an approach where patients are seen as active co-creators and knowledge carriers, and as partners. This approach evolves over time, and the professionals express:

"Their knowledge is the future. So, the professionals need to start including patients to move forward and develop and improve quality in care, which we have seen and collaboration has led to in a very good way."

This inclusive approach also expands the number of professionals in response to the group's emerging needs, all to support the patients' self-management: "It is very little practical doing, but instead is more about teaching the patient to do something himself." Finding inner motivation and offering choices without blaming the patients are conscious caregiver strategies that the approach also includes to enable co-creation.

The patients who participate in the COPD-web development feel they are important and listened to, and that their knowledge and opinions are highly valued. They describe this participation as completely different from previous care experiences, where the physician is considered to know best. The patients feel truly proud of their work by helping to spread knowledge.

\section{Responsibility and Motivation as Driving Forces}

Developing a digital COPD-web includes responsibility and motivation as driving forces for the professionals and patients. The goal is for both evidence-based knowledge and patient experiences to be easily accessible for people with COPD, their close relatives, new staff, primary care professionals and others who are interested. A crucial driving force is thus to highlight the experience of living with COPD. The professionals also feel responsible for communicating knowledge based on a holistic view of patients' needs.

The motivation for the COPD-web is changing healthcare conditions, where more and more responsibility for caring for patients with COPD is transferred to primary care. This, together with the increased number of patients with COPD, is a great challenge for the future. The participants are also driven by ensuring the quality of the available information, that it is based on evidence and best practice and that it remains even after the team disperses:

"But we have to assure the quality and therefore we made these films. Just because if a nurse, social worker, dietician, occupational therapist ends their service, everyone must know what the other has been talking about. Then, you can build on your own. That is when the COPDschool on the web came to be."

The COPD-web is described as a more effective way of sharing knowledge, but there is an awareness that its digital format does not fit all. At the same time, there is an understanding that some patients are at work and have difficulties attending physical group meetings, while others are unable to attend because of their COPD. From both these aspects, the digital website is an opportunity that motivates the participants in developing the COPDweb.

A sense of responsibility pushed the various professionals to participate in the team, even though they have different personal responsibilities and limited time. The motivation and driving force provided by the project manager improved the outcome as follows: "let's do this ... it has been energy and joy ... she has come up with ideas suggestions and wanted us to tag along."

Motivation is reinforced both through pride in belonging to the group and by the interest the professionals have in meeting other actors in society, both nationally and internationally.

\section{Digital Technology as a Knowledge Arena}

Developing the COPD-web involves understanding digital technology as a source of knowledge with possibilities and limitations. Some benefits described include that the COPD-web featured information available to anyone and when needs arise. According to the patients, this possibility foremost reduces anxiety. Another advantage is the possibility to offer a wider range of subjects than in traditional group education: the COPD-web contains a large selection of texts, films and practical advice on, for example, training or how to inhale the medicine. There are prejudices in society that elderly people do not have access 
to technology or technical knowledge, which both the patients and professionals opposed.

"Everyone does not have access to technology, knowledge or simply does not want to, so it is important to have a mix of physical meetings in the COPDschool and COPD-web."

Still, while the digital website is an arena of knowledge with opportunities, the group affiliation is lost. The professionals' future thoughts are to develop a COPD-web chat function, virtual rounds and sensors. There is also a desire to have digital meetings with patients, follow their values and give individual support. Furthermore, there remains the challenge of keeping the website up to date. The developing process with the digital technology is an ongoing process for both the patients and the professionals involved.

\section{Discussion}

The result will be discussed based on the phenomenon "developing a digital COPD-web" from the professional and patient perspectives, in relation to collaboration, cocreation, utilization and sustainable learning.

The results feature a constructive collaboration between a multidisciplinary COPD-team and patients as co-creators in an ongoing process. Other studies have suggested that patient involvement is important to understanding user needs. ${ }^{3,24}$ Based on patients' needs, the professionals were linked to the COPD-web team. Part of the driving force to develop the COPD-web was an inclusive approach that involves everyone.

In this study, a prerequisite was collaboration across interdisciplinary borders to meet user needs and to take overall responsibility to provide opportunities for learning. The COPD-web was also recognized nationally and internationally, contributing to a sense of pride in its development group. Additionally, the multidisciplinary team was led by a person with great commitment and the ability to bring everyone into the work process; trust in leadership entails followers daring to actively solve problems, which has been linked to increased satisfaction and engagement

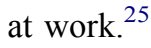

A vision of utilization based on a person-centred approach emerged in this digital platform's creation. Other research show that a holistic approach that meets the needs of patients is required. Further, communication between patients and professionals is also important to enhance care quality. ${ }^{9}$ Within the group of professionals and patients, there was trust in everyone's skills and willingness to achieve the best COPD-web. The personcentred approach was further developed with the patients serving as co-creators in the COPD-web's development, as the professionals listened to the patients' experiences and required their critical review of the website's content and usability.

The results demonstrated an awareness of creating conditions for other possibilities to meet patient needs and to support learning about COPD and selfmanagement in everyday life, for example, as to save energy in coping with fatigue.

Implementation of a self-management program with target interventions aimed to inform and support patients with chronic illness to manage daily life through involvement and self-control in their treatment is requested. ${ }^{8,26}$ The driving force was reaching out with information about the illness, so the COPD-team initiated a digital solution. Patient involvement was a crucial factor to attaining this goal to improve the knowledge, awareness and understanding of COPD by increasing accessibility, transferring knowledge remotely and improving efficiency. This project touched the core of the complexity of living with COPD by raising both "what" and "how" questions, which is challenging in didactic studies. ${ }^{27}$

eHealth solutions are one way to promote selfmanagement over time by engaging patients and providing a basis for professionals to follow a more person-centred approach. $^{20,28,29}$ The digital web design ensured that a wide range of knowledge was available, based on patients' needs and reviewed from evidence- and patient perspectives. In addition, the information remained available, despite someone leaving the COPD-team. The COPD-web also enabled information useful at the physical COPDschool. Furthermore, other professionals within different contexts, patients and their relatives had access to the COPD-web, as it was available at any time and could be repeatedly accessed, proving rather useful.

However, the results also showed a fear that physical COPDschool meetings would be reduced. Both the professionals and the patients believed that physical meetings were important, therefore the COPD-web may be a valuable complement and not to been seen as a replacement. There was also an awareness that the website's information could quickly become outdated and constantly needed updating.

The results further reflected the team's intentions for sustainable learning. Learning takes place in a professional collaboration that clarifies roles and responsibilities. 
Therefore, the patients, their relatives and the professionals offered possibilities to attain sustainable learning through available, comprehensible education on the COPD-web. For learning to take place, though, webbased education must be comprehensible, put into the individual context and linked to prior understanding. Reflection over experiences, in relation to a changeable life with illness, is also crucial for a more genuine learning. ${ }^{27}$ Genuine learning, in this case, is that which changes the person's understanding of themselves as a person living with COPD. Web-based support for selfmanagement alone is insufficient to achieving sustainable behaviour change for optimal health improvement. ${ }^{9}$ However, web-based support is an important tool to increase access to self-management strategies and a complement to group-based education with support from other participants and professionals. ${ }^{29,30}$

This study's results further defended that the physical presence of the COPDschool enabled reflections. Group education requires professionals to have pedagogical education to achieve effects. ${ }^{31}$ The question, then, was how a website also becomes a learning arena, or more than an information platform. The patients in this study required a digital venue with the possibility of reflective conversations, leading to a renewed understanding of themselves and life with COPD. The COPD-web is thus an example of a digital platform that grants freedom to access information when and as often as necessary.

\section{Strengths and Limitations}

We considered the focus on lived experiences in RLR a suitable method to give a deeper understanding of the studied phenomenon. The phenomenon in this study, developing a digital COPD-web was studied by data collected through interviews. A strength of the study was that the interviews were conducted face to face in groups and individually with both patients and professionals. During the interviews, the atmosphere was open and everyone was given the opportunity to speak. The interviewers have much experience with researching and interviewing, both individually and in groups, and the data contained rich and detailed information as a result. The chosen method (RLR) also required an open and reflective approach regarding understanding of the phenomenon during the research process, demanding researcher bridling in relation to the phenomenon to ensure validity. ${ }^{32}$ Another strength was that the researchers did not participate in the COPD-web's development, which may have facilitated the bridling process. The transferability of the findings was possible through a rich variation of experiences, ${ }^{32}$ which potentially contributed to the results' generalizability and transfer to similar groups of patients with long-term illnesses and high self-care demands. As with all qualitative studies, the transferability of our results to a similar context and to other countries must be valued and assessed by the reader. This study was performed in a Swedish context, which might be a limitation.

\section{Conclusion}

The study results indicate that professionals and patients together, in an ongoing reviewing process through an interprofessional holistic approach, is a key concept to develop a digital COPD-web. The involvement of persons living with COPD as co-creators and the careful analysis of their point of views and experiences enable their perspectives to be built into the digital website, and will most likely contribute to a tool that has the potential to be adopted in everyday life and usability in practice. This is important if the goal is to develop a support tool with a person-centred approach. The collaboration between the multidisciplinary team and the patients creates new knowledge and understanding about daily living with COPD, ie, entails learning for all involved.

However, there is a risk with digital technology as a knowledge arena. A risk that patients are left even more alone with existential issues and in their learning to integrate the knowledge of illness and treatment into their lives, eg, because there are no opportunities for further conversation. The patients may have the knowledge of their condition and treatment from the COPD-web but no idea of how to apply that knowledge to their situation. Digital resources in the future might create time and space for reflective conversations in a COPD-web with virtual chatrooms. The caregivers have a great responsibility to take this into consideration.

\section{Ethical Approval and Informed Consent}

The study conformed to the principles of the Declaration of Helsinki. ${ }^{33}$ Prior to interviews, all participants received written and oral information about the study. Prior to being included in this study oral and written consent was obtained from the participants. All participants also provided informed consent to publish anonymized data 
material, including quotes. The study was approved by the National Ethical Review board (Dnr: 2019-02293).

\section{Acknowledgments}

The authors would like to thank the COPD-team at Skaraborg Hospital Skövde and the patients who voluntarily participated in the study; together they made this research possible.

\section{Author Contributions}

All authors made a significant contribution to the work reported, whether that is in the conception, study design, execution, acquisition of data, analysis and interpretation, or in all these areas; took part in drafting, revising or critically reviewing the article; gave final approval of the version to be published; have agreed on the journal to which the article has been submitted; and agree to be accountable for all aspects of the work.

\section{Funding}

The study was conducted with support from the Skaraborg Institute, Sweden (Dnr. 19/1034) and the Research and Development Centre, Skaraborg Hospital Skövde, Sweden.

\section{Disclosure}

The authors have no conflicts of interest to declare.

\section{References}

1. Barnett K, Mercer SW, Norbury M, Watt G, Wyke S, Guthrie B. Epidemiology of multimorbidity and implications for health care, research, and medical education: a cross-sectional study. Lancet. 2012;380(9836):37-43. doi:10.1016/s0140-6736(12)60240-2

2. Stellefson ML, Shuster JJ, Chaney BH, et al. Web-based health information seeking and eHealth literacy among patients living with chronic obstructive pulmonary disease (COPD). Health Commun. 2018;33(12):1410-1424. doi:10.1080/10410236.2017.1353868

3. Tistad M, Lundell S, Wiklund M, Nyberg A, Holmner A, Wadell K. Usefulness and relevance of an eHealth tool in supporting the self-management of chronic obstructive pulmonary disease: explorative qualitative study of a cocreative process. JMIR Hum Factors. 2018;5(4):e10801. doi:10.2196/10801

4. Himes BE, Weitzman ER. Innovations in health information technologies for chronic pulmonary diseases. Respir Res. 2016;17:38. doi:10.1186/s12931-016-0354-3

5. Metting E, Schrage AJ, Kocks JW, Sanderman R, van der Molen T. Assessing the needs and perspectives of patients with asthma and chronic obstructive pulmonary disease on patient web portals: focus group study. JMIR Form Res. 2018;2(2):e22. doi:10.2196/ formative. 8822

6. Marx G, Nasse M, Stanze H, Boakye SO, Nauck F, Schneider N. Meaning of living with severe chronic obstructive lung disease: a qualitative study. BMJ Open. 2016;6(12):e011555. doi:10.1136/ bmjopen-2016-011555
7. Lundell S COPD in Primary Care: Exploring Conditions for Implementation of Evidence-Based Interventions and eHealth [doctoral thesis, comprehensive summary]. Umeå: Umeå University medical dissertations, Umeå universitet; 2018.

8. Bourne C, Kanabar P, Mitchell K, et al. A self-management programme of activity coping and education - SPACE for COPD(C) - in primary care: the protocol for a pragmatic trial. BMJ Open. 2017;7 (7):e014463. doi:10.1136/bmjopen-2016-014463

9. Stoilkova-Hartmann A, Franssen FME, Augustin IML, Wouters EFM, Barnard KD. COPD patient education and support achieving patient-centredness. Patient Educ Couns. 2018;101 (11):2031-2036. doi:10.1016/j.pec.2018.05.024

10. Nyberg A, Tistad M, Wadell K. Can the COPD web be used to promote self-management in patients with COPD in Swedish primary care: a controlled pragmatic pilot trial with 3 month- and 12 month follow-up. Scand J Prim Health Care. 2019;37(1):69-82. doi:10.1080/02813432.2019.1569415

11. World Health Organization. The top 10 causes of death. World Health Organization; Available from: https://www.who.int/en/news-room/factsheets/detail/the-top-10-causes-of-death. Accessed December 09, 2021.

12. The National Board of Health and Welfare. National guidelines for treatment of asthma and COPD - support for management. 2018. Available from: https://www.socialstyrelsen.se/globalassets/share point-dokument/artikelkatalog/nationella-riktlinjer/2018-1-36.pdf. Accessed March 24, 2021

13. McCarthy B, Casey D, Devane D, Murphy K, Murphy E, Lacasse Y. Pulmonary rehabilitation for chronic obstructive pulmonary disease. Cochrane Database Syst Rev. 2015;2. doi:10.1002/14651858. CD003793.pub3

14. Mannino DM, Thorn D, Swensen A, Holguin F. Prevalence and outcomes of diabetes, hypertension and cardiovascular disease in COPD. Eur Respir J. 2008;32(4):962-969. doi:10.1183/ 09031936.00012408

15. Yohannes AM, Alexopoulos GS. Depression and anxiety in patients with COPD. Eur Respir Rev. 2014;23(133):345-349. doi:10.1183/ 09059180.00007813

16. Ekman I, Swedberg K, Taft C, et al. Person-centered care-ready for prime time. Eur J Cardiovasc Nurs. 2011;10(4):248-251. doi:10.1016/j.ejcnurse.2011.06.008

17. Frisch NC, Rabinowitsch D. What's in a definition? Holistic nursing, integrative health care, and integrative nursing: report of an integrated literature review. J Holist Nurs. 2019;37(3):260-272. doi:10.1177/0898010119860685

18. Kaptein AA, Fischer MJ, Scharloo M. Self-management in patients with COPD: theoretical context, content, outcomes, and integration into clinical care. Int J Chron Obstruct Pulmon Dis. 2014;9:907-917. doi:10.2147/copd.s49622

19. Kruis AL, Smidt N, Assendelft WJ, et al. Integrated disease management interventions for patients with chronic obstructive pulmonary disease. Cochrane Database Syst Rev. 2013;10. doi:10.1002/ 14651858.CD009437.pub2

20. Ali L, Fors A, Ekman I. Need of support in people with chronic obstructive pulmonary disease. J Clin Nurs. 2018;27:e1089-e1096. doi:10.1111/jocn.14170

21. Bate P, Robert G. Experience-based design: from redesigning the system around the patient to co-designing services with the patient. Qual Saf Health Care. 2006;15(5):307-310. doi:10.1136/qshc.2005.016527

22. Boyd $\mathrm{H}$, McKernon S, Mullin B, Old A. Improving healthcare through the use of co-design. N Z Med J. 2012;125(1357):76-87.

23. Dahlberg K, Dahlberg H, Nyström M. Reflective Lifeworld Research. Lund: Studentlitteratur; 2008.

24. Kayser L, Kushniruk A, Osborne RH, Norgaard O, Turner P. Enhancing the effectiveness of consumer-focused health information technology systems through eHealth literacy: a framework for understanding users' needs. JMIR Hum Factors. 2015;2(1):e9. doi:10.2196/humanfactors.3696 
25. Dirks KT, Ferrin DL. Trust in leadership: meta-analytic findings and implications for research and practice. J Appl Psychol. 2002;87 (4):611-628. doi:10.1037/0021-9010.87.4.611

26. Newman S, Steed L, Mulligan K. Self-management interventions for chronic illness. Lancet. 2004;364(9444):1523-1537. doi:10.1016/ S0140-6736(04)17277-2

27. Berglund M. Learning turning points-in life with long-term illnessvisualized with the help of the life-world philosophy. Int J Qual Stud Health Well-Being. 2014;9:22842. doi:10.3402/qhw.v9.22842

28. Midlov P, Nilsson PM, Bengtsson U, et al. PERson-centredness in hypertension management using information technology (PERHIT): a protocol for a randomised controlled trial in primary health care. Blood Press. 2019:1-8. doi: 10.1080/08037051.2019.1697177

29. Nyberg A, Wadell K, Lindgren H, Tistad M. Internet-based support for self-management strategies for people with COPD-protocol for a controlled pragmatic pilot trial of effectiveness and a process evaluation in primary healthcare. BMJ Open. 2017;7(7):e016851. doi:10.1136/bmjopen-2017-016851
30. North M, Bourne S, Green B, et al. A randomised controlled feasibility trial of E-health application supported care vs usual care after exacerbation of COPD: the RESCUE trial. NPJ Digit Med. 2020;3 (1):145. doi:10.1038/s41746-020-00347-7

31. Andersson S, Berglund M, Vestman C, Kjellsdotter A. Experiences of specially trained personnel of group education for patients with type 2 diabetes-A lifeworld approach. Nurs Open. 2019;6(2):635-641. doi:10.1002/nop2.248

32. Dahlberg K, Dahlberg H. Phenomenology in Practice, Phenomenological Research from a Scandinavian Perspective. 1st ed. Liber; 2019:155-189.

33. World Medical Association. Declaration of Helsinki ethical principles for medical research involving human subjects. 2008. Available from: http:/www.wma.net/en/30publications/10policies/b3/index.html. Accessed March 24, 2021.
Journal of Multidisciplinary Healthcare

\section{Publish your work in this journal}

The Journal of Multidisciplinary Healthcare is an international, peerreviewed open-access journal that aims to represent and publish research in healthcare areas delivered by practitioners of different disciplines. This includes studies and reviews conducted by multidisciplinary teams as well as research which evaluates the results or conduct of such teams or healthcare processes in general. The journal
Dovepress

covers a very wide range of areas and welcomes submissions from practitioners at all levels, from all over the world. The manuscript management system is completely online and includes a very quick and fair peer-review system. Visit http://www.dovepress.com/testimonials. php to read real quotes from published authors. 